\section{GREQAM}

Groupement de Recherche en Economie Quantitative d'Aix-Marseille - UMR-CNRS 6579

Ecole des Hautes études en Sciences Sociales Universités d'Aix-Marseille II et III
Document de Travail

n²011-49

\title{
Coordination with Communication under Oath
}

Nicolas Jacquemet

Stéphane Luchini

Jason F. Shogren

Adam Zylbersztejn

May 2012 


\title{
Coordination with Communication under Oath*
}

\author{
Nicolas Jacquemet ${ }^{\dagger} \quad$ Stéphane Luchini ${ }^{\ddagger}$ \\ Jason F. Shogren ${ }^{\S} \quad$ Adam Zylbersztejn
}

May 2012

\begin{abstract}
Herein we explore whether the social psychology theory of commitment via a truth-telling oath can reduce coordination failure. Using a classic sequential coordination game, we ask all players to sign voluntarily a truth-telling oath before playing the game with cheap-talk communication. Three results emerge with commitment-via-the-oath: (1) coordination increased by nearly 50 percent; (2) senders' messages were significantly more truthful and actions more efficient, and (3) receivers' trust of messages increased.
\end{abstract}

Keywords: Coordination game; Cheap talk communication; Oath.

JEL Classification: C72; D83.

\section{Introduction}

A coordination game captures the idea that value can be created when people coordinate their noncooperative actions in a strategic environment (see Schelling, 1960; Cooper, DeJong, Forsythe, and Ross, 1990). If people coordinate their otherwise sovereign actions, they can achieve the first

*We thank Tore Ellingsen and the participants of the Environmental \& Resource Economics Seminar at the University of Manchester School of Social Science for valuable comments, and to Maxim Frolov and Ivan Ouss for their assistance in running the experiments. Financial support of the chair "Economie Publique et Développement Durable" (Aix-Marseille University) is gratefully acknowledged. Nicolas Jacquemet acknowledges the Institut Universitaire de France. Stéphane Luchini thanks the MIT Sloan School of Management for its hospitality. Adam Zylbersztejn is grateful to the Collège des Ecoles Doctorales de l'Université Paris 1 Panthéon-Sorbonne, the Alliance Program and the Columbia University Economics Department for their financial and scientific support.

${ }^{\dagger}$ Paris School of Economics and University Paris I Panthéon-Sorbonne. Centre d'Economie de la Sorbonne, 106 Bd. de l'Hôpital, 75013 Paris. Nicolas.Jacquemet@univ-paris1.fr

${ }^{\ddagger}$ GREQAM-CNRS, Centre de la Vieille Charité, 13236 Marseille Cedex 02. stephane.luchini@univmed.fr

${ }^{\S}$ Department of Economics and Finance, University of Wyoming, Laramie, WY 82071-3985, United States; and Department of Economics, Umeå University, S 90187 Umeå, Sweden. JRamses@uwyo.edu

`Paris School of Economics, University Paris I Panthéon-Sorbonne. Centre d'Economie de la Sorbonne, 106 Bd. de l'Hôpital, 75013 Paris. adam.zylbersztejn@malix.univ-paris1.fr 
best equilibrium among many suboptimal ones. Coordination failure arises when people fail to realize the first best outcome due to strategic uncertainty - the risk associated with not knowing how your opponent will play the game (see, e.g., the survey by Devetag and Ortmann, 2007). Better communication between players is the most frequently prescribed institution to overcome coordination failure. Accumulated evidence shows (i) communication can improve efficiency; but (ii) many coordination failures still remain because the messages are non-binding cheap talk, i.e., there are no real economic consequences to players who do not act in accordance to the message (see, e.g., Cooper, DeJong, Forsythe, and Ross, 1992; Parkhurst, Shogren, and Bastian, 2004).

Herein we explore whether we can create a coordination game environment in which people are committed to match words with actions. Following the social psychology theory of commitment, we use a truth-telling oath procedure introduced by Jacquemet, Joule, Luchini, and Shogren (2009) to strengthen the link between players' communications and actions: each player voluntarily signs an oath to tell the truth before he or she enters the lab. Commitment theory and experimental evidence has shown people are more likely to match actions with words when they have freely chosen to commit themselves to doing them through a prior action (see Joule and Beauvois, 1998) 11 Our hypothesis is that the prior action -an oath to tell the truth- will create commitment that will enhance the power of cheap talk communication thereby reducing strategic uncertainty and increasing coordination.

In an experimental design using the classic sequential coordination game of a sender and a receiver (see Selten, 1975, Rosenthal, 1981) 2 ${ }^{2}$ our results are that coordination increases by over 50 percent within the oath treatment. The oath increases coordination by changing the behavior of the sender-his messages are now more truthful and focused on efficiency, and his choices are more efficient. These findings are in line with related economic experiments. People who make promises about future actions after pre-play communication are more likely to keep them (see e.g. Ellingsen and Johannesson, 2004, Charness and Dufwenberg, 2006; Vanberg, 2008). The oath also changed the behavior of the receiver. Although many remained cautious, more receivers trusted the messages about how the sender will play the game. This finding reveals the relative nature of commitment and communication: nearly all senders committed to matching deeds with words, whereas fifty percent of the receivers still remained wary.

\footnotetext{
${ }^{1}$ In so called low-ball experiments, for instance, subjects are asked their willingness to perform a target behavior before knowing the full costs of the target behavior. Data show that low-balling significantly increases compliance relative to cases in which individuals are asked to perform the target behavior directly. See Cialdini, Bassett, Miller, and Miller (1978) for the seminal experiment, Cialdini and Sagarin (2005) for an overview and Joule and Beauvois (1998) for a comprehensive work on procedures that create commitment.

${ }^{2}$ In sequential games, coordination failures arise from strategic uncertainty; See for instance Beard and Beil (1994); Beard, Beil, and Mataga (2001); Goeree and Holt (2001); Jacquemet and Zylbersztejn (2010).
} 
Table 1: The experimental game

\begin{tabular}{cccc|c|} 
& \multicolumn{2}{c}{ Sender } \\
\cline { 3 - 4 } & \multicolumn{2}{c}{$l$} & \multicolumn{1}{c}{$r$} \\
\cline { 3 - 4 } Receiver & $L$ & $(9.75 ; 3)$ & $(9.75 ; 3)$ \\
\cline { 3 - 4 } & $R$ & $(3 ; 4.75)$ & $(10 ; 5)$ \\
\cline { 3 - 4 } & & &
\end{tabular}

\section{Description of the experiment}

\subsection{The game}

Coordination game. We rely on the normal form game presented in Table $1^{3}$ The game involves two players: player $\mathrm{A}$, who chooses between actions $R$ and $L$, and player $\mathrm{B}$, who chooses between actions $r$ and $l$. If $R$ is chosen by player A, player B can maximize both players' payoffs by selecting action $r$. Alternatively, player B may choose action $l$, which slightly undermines her own payoff and furthermore sharply decreases player A's payoff. If, in turn, player A chooses $L$, then both players' payoffs do not depend on player B's decision - payoffs are the same whatever action is chosen.

From the theoretical standpoint, $(R, r)$ is a Pareto dominant and a pure-strategy perfect Nash equilibrium. $(L, l)$ also happens to be a Nash equilibrium, which is nonetheless imperfect - since it involves a weakly dominated strategy $l$ from player B. Therefore, player A's best choice is $R$ should player B be an own-payoff maximizer who seeks to use the dominant strategy $r$, and $L$ otherwise. Furthermore, action $L$ involves the least strategic uncertainty for player A. Depending on the stakes, player A's expected payoff from an unreliant decision $L$ can dominate the expected payoff of a reliant decision $R$, even if the probability that player $\mathrm{B}$ uses dominated strategies is very low ${ }^{4}$

Pre-play communication. Prior to decision making, player B (hereafter, the sender) transmits a cheap talk signal to player A (hereafter, the receiver), indicating (truthfully or not) her intended

\footnotetext{
${ }^{3}$ This payoff structure appears as Treatment 1 in the genuine experiment of Beard and Beil (1994). Among several reported payoff schemes, this one induces the most striking behavior among participants: (i) the frequency of player As' unreliant choices related to this treatment is remarkable: $65.7 \%$, and (ii) this is the only treatment where deviations from the dominant strategy by player Bs were observed (in $17 \%$ of all cases where player A made a reliant decision $R$ ). (Jacquemet and Zylbersztejn, 2010) report that roughly 50\% of all player As' decisions are unreliant, and that player Bs use dominated strategy in about $20 \%$ of all cases, when this simultaneous-move game is repeated. Jacquemet and Zylbersztejn (2011) show that these results are robust to a change in the payoff structure that eliminates inequality in payoffs between players.

${ }^{4}$ The cut-off probability of decision $l$ by player B which makes player A indifferent between actions $L$ and $R$ equals 0.036 .
} 
decision. We are interested in a fixed-form communication, in which senders choose between three messages: "I will choose $r$ ", "I will choose l", "I will either choose $l$ or $r$ ". The first two messages are informative, while the last one is uninformative in what concerns senders' intentions. The first of these signals has important theoretical properties: namely, it is self-committing, but not self-signalling (Farrell and Rabin, 1996; Aumann, 1990). It is self-committing because, if trusted, it induces the receiver to choose $R$, to which the sender's best response is $r$ - exactly as the message announces. However, it is not self-signalling, since it does not reveal sender's true intentions: she may use message "I will choose $r$ " to persuade her partner to choose $R$, and take any action afterwards. Hence, communication in our game provides some reassurance to the receiver about the rationality of the sender. If individuals have a weak preference for truthfulness, senders always reveal their true intention and use message "I will choose $r$ " to signal that they disregard the weakly dominated strategy. One-way communication between partners is generally found to improve efficiency in coordination games by reducing strategic uncertainty. For an insightful review of related literature see, e.g., Crawford (1998); Ellingsen and Östling (2010).

\subsection{Experimental design}

Baseline treatment (NoOath). Each experimental session consists of 10 rounds of the game presented in Table 1. Roles are fixed, so that each participant takes 10 decisions as either receiver or sender. After each interaction, pairs are rematched according to a perfect stranger round-robin procedure that guarantees that each pair of subjects may interact at most once throughout the entire experiment 5 For the sake of avoiding the end-game effects, we do not reveal to participants the exact number of rounds, but only inform in the experimental instructions that there will be several of them. At the beginning of each round, the sender sends one of the three messages to the receiver by clicking on a relevant button on her computer screen. We explain to the subjects that messages sent by senders do not affect their payoffs, and that they can be followed by any decisions. Once the receiver has confirmed receiving the message, the game moves to the decisionmaking stage, where the receiver chooses between $R$ and $L$, while the sender - between $r$ and $l$. Instructions inform the participants that decision is first taken by the receiver, then by the sender, and the final payoff depends only on the receiver's decision should $L$ has been chosen, and on both partners' decisions otherwise. At the end of every round, each subject is only informed about her own payoff. Next, individuals are informed that either another round is about to start, or that the experiment ends 6

\footnotetext{
${ }^{5}$ This procedure, also known as rotation matching, is optimal for our experimental design: for a given number of players and the one-shot nature of each interaction between subjects, it maximizes the number of rounds. See Kamecke (1997) and Duffy and Feltovich (2002) for a related discussion.

${ }^{0}$ The material used in the experiment is available from the authors upon request.
} 
Figure 1: OAth Form USED in the Experiment

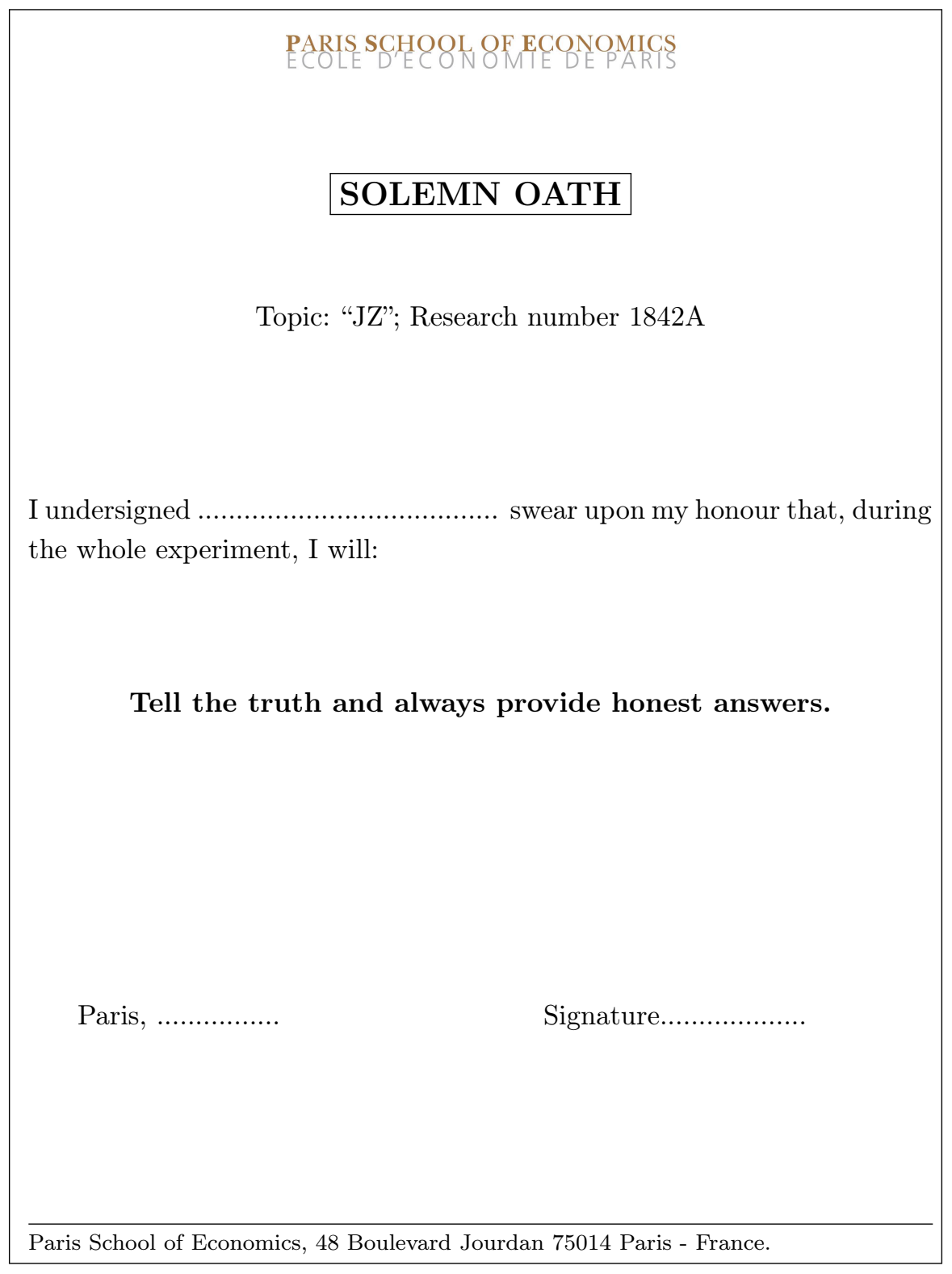

Oath treatment. This treatment uses an identical experimental environment as the baseline treatment, except that each subject is asked to sign an explicit oath before entering the lab (see (see Jacquemet, Joule, Luchini, and Shogren, 2009; Jacquemet, James, Luchini, and Shogren, 2010). The oath is implemented as follows: each subject enters alone and is directed to a monitor at the front of the laboratory. The monitor then offers each subject a form to sign entitled "solemn oath" as presented in Figure 17 The Paris School of Economics logo on the top of the form

\footnotetext{
${ }^{7}$ The word "oath" is written on the form and read by the subject, but never said aloud.
} 
and the address at the bottom indicate that it is an official paper; the topic designation and the research number were added so to ensure the credibility. The monitor explicitly points out to the subject before she reads the form that she is free to sign the oath or not, and that participation and earnings are not conditional on signing the oath (subjects are, however, not informed about the topic of the experiment when asked to take the oath). The subject reads the form, which asks whether she agrees "to swear upon my honor that, during the whole experiment, I will tell the truth and always provide honest answers" (in bold in the original form). Regardless of whether the subject signs the oath, he or she is thanked and invited to enter the lab. The exact wording used by the monitors to offer the oath to respondents was scripted to standardize the phrasing of the oath. One monitor stayed in the lab until all subjects had been presented with the oath, to avoid communication prior to the experiment. Subjects waiting their turn could neither see nor hear what was happening at the oath-desk.

\subsection{Experimental procedures}

We run six experimental sessions (three for each experimental condition), each of them involving 20 subjects -10 receivers and 10 senders ${ }^{8}$ In the oath treatment, subjects first come one by one to the oath-desk and are exposed to the above described procedure. Although signing the oath was not mandatory, a large majority of subjects accepted to do so. Six subjects did not take an oath. This leads to a $90 \%$ acceptance rate. This is in line with previous experiments involving an oath procedure (see Jacquemet, Joule, Luchini, and Shogren, 2009; Jacquemet, James, Luchini, and Shogren, 2010) 9 We apply an intention to treat strategy, so that these six subjects are kept in the statistical analysis - given the number of observations this does not affect the statistical results, though.

In both treatments, subjects sign an individual consent form (mandatory and distributed publicly) before entering the lab. Participants are then randomly assigned to their computers and asked to fill in a small personal questionnaire containing basic questions about their age, gender, education, etc. The written instructions are then read aloud. Players are informed that they will play some (unrevealed) number of rounds of the same game, each round with a different partner, and that their own role will not change during the experiment. Before starting, subjects are asked to fill in a quiz assessing their understanding of the game they are about to play. Once the quiz and all remaining questions are answered, the experiment begins. Prior to the first round, players are randomly assigned to their roles - either receiver or sender. Subsequently, they are anonymously and randomly matched to a partner. Then, the sender sends a message to the receiver, after which they are both asked for their choices, $R$ or $L$ for receivers, and $r$ or $l$ for senders. At the end of

\footnotetext{
${ }^{8}$ The data for the baseline treatment come from the communication treatment of Jacquemet and Zylbersztejn (2010).

${ }^{9}$ This is also a standard acceptance rate for commitment experiments (see Joule and Beauvois, 1998, Burger, 1999).
} 
Table 2: Aggregate Results

\begin{tabular}{|c|c|c|c|c|c|c|c|c|c|c|c|}
\hline & \multicolumn{10}{|c|}{ Round } & \multirow[t]{2}{*}{ Overall } \\
\hline & 1 & 2 & 3 & 4 & 5 & 6 & 7 & 8 & 9 & 10 & \\
\hline \multicolumn{12}{|l|}{ No oath } \\
\hline Coordination $(L, l)$ or $(R, r)$ & 56.7 & 46.7 & 60.0 & 63.3 & 66.7 & 70.0 & 80.0 & 66.7 & 66.7 & 83.3 & 66.0 \\
\hline Efficient outcome $(R, r)$ & 43.3 & 26.7 & 50.0 & 50.0 & 50.0 & 60.0 & 66.7 & 60.0 & 56.7 & 63.3 & 52.7 \\
\hline Miscoordination $(L, r)$ & 36.7 & 43.3 & 40.0 & 33.3 & 16.7 & 20.0 & 20.0 & 23.3 & 30.0 & 10.0 & 27.3 \\
\hline Miscoordination $(R, l)$ & 6.7 & 10.0 & 0.0 & 3.3 & 16.7 & 10.0 & 0.0 & 10.0 & 3.3 & 6.7 & 6.7 \\
\hline \multicolumn{12}{|l|}{ Oath } \\
\hline Coordination $(L, l)$ or $(R, r)$ & 73.3 & 80.0 & 83.3 & 86.7 & 80.0 & 80.0 & 76.7 & 80.0 & 83.3 & 70.0 & 79.3 \\
\hline Efficient outcome $(R, r)$ & 70.0 & 70.0 & 73.3 & 80.0 & 76.7 & 73.3 & 76.7 & 76.7 & 83.3 & 70.0 & 75.0 \\
\hline Miscoordination $(L, r)$ & 26.7 & 20.0 & 16.7 & 10.0 & 16.7 & 16.7 & 23.3 & 20.0 & 13.3 & 20.0 & 18.3 \\
\hline Miscoordination $(R, l)$ & 0.0 & 0.0 & 0.0 & 3.3 & 3.3 & 3.3 & 0.0 & 0.0 & 3.3 & 10.0 & 2.3 \\
\hline
\end{tabular}

Note. Columns 1-10 summarize the frequencies of outcomes (defined in rows) as $\%$ of all outcomes observed in each round of a given experimental treatment. The last column provides overall results.

every round, each participant is informed solely about her own payoff. Once all pairs complete a round of the game, subjects are informed whether a new round starts. If this is the case, pairs are rematched. Otherwise, a single round is randomly drawn and each player receives the amount in Euros corresponding to her gains in that round, plus a show-up fee equal to 5 Euros.

All sessions took place in the lab of University Paris 1 (LEEP) in between June 2009 and January 2012. The recruitment of subjects has been carried out via LEEP database among individuals who have successfully completed the registration process on Laboratory's website 10 The experiment involved a total group of 120 subjects, 72 males and 48 females. 102 of them are students, among which 58 subjects are likely to have some background in game theory due to their field of study 11 28\% never took part in any economic experiment in LEEP before. Participants' average age is roughly 24. No subject participated in more than one experimental session. Each session lasted about 45 minutes, with an average payoff of approximately 12 Euros.

\section{Results}

Table 2 summarizes aggregate results by round from both treatments. We see our first key result: the likelihood that players coordinated to the optimal Pareto-efficient outcome increased by nearly 50 percent due to oath - to 75.0 percent optimal coordination with the oath from $52.7 \%$ without.

\footnotetext{
${ }^{10}$ The recruitment uses ORsee (Greiner, [2004); the experiment is computerized through a software developed under ReGATE (Zeiliger, 2000).

${ }^{11}$ Disciplines such as economics, engineering, management, political science, psychology, mathematics applied in social science, mathematics, computer science, sociology, biology.
} 
Figure 2: Communication Behavior of senders by treatment

(a) Informative messages

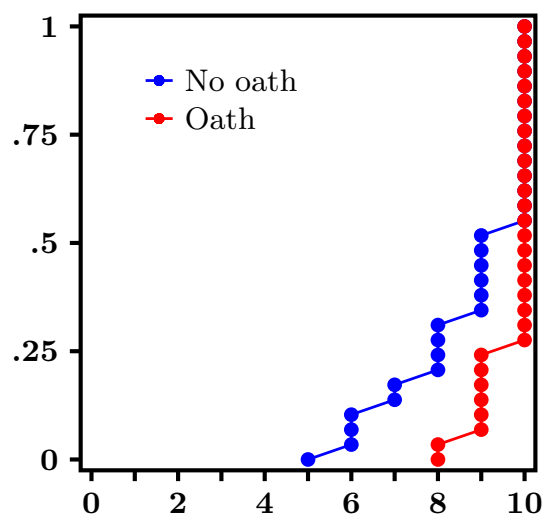

(b) "I will choose $r$ "

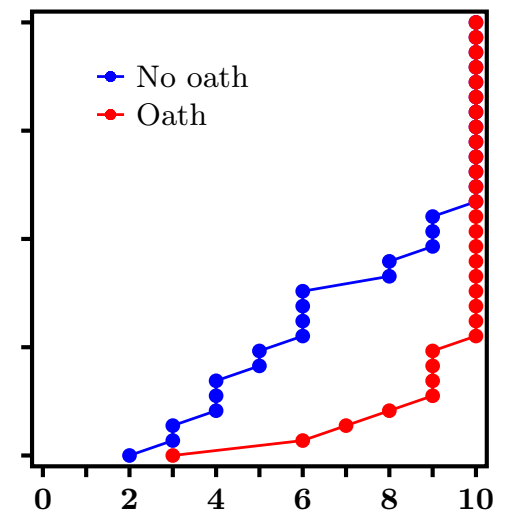

(c) "I will choose $l$ "

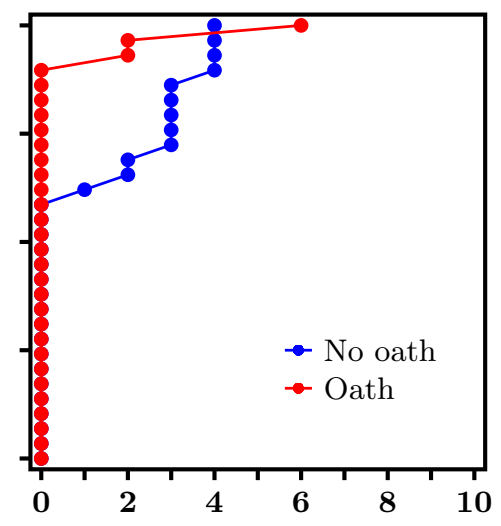

Number of messages sent by subjects

Each type of suboptimal coordination -either $(L ; r)$ or $(R ; l)$ - was less likely in the oath treatment than in the baseline. Accounting for both optimal and suboptimal coordination, the commitmentvia-the-oath contributes to coordinating players' actions - Nash equilibria increase to 79.3 percent in the oath treatment from $66 \%$ in the baseline.

Result 1 Commitment via the truth-telling oath increased coordination on the socially optimal Nash equilibria to 75 percent of games from 53 percent without the oath.

The increase of coordination induced by the oath is explained by significant changes in individual behavior. First, we look at the patterns of communication by senders. Figures 2, a, 2, b and 2 . c show the empirical distribution functions (EDF) of the number of messages sent by subjects in the role of senders over all 10 decision periods. Each bullet inside the graph indicates an individual, on the $x$-axis we present the number of messages she has sent (between 0 and 10), the $y$-axis represents the probability of observing an individual who has sent at most a given number of messages. Figure 2 a depicts the empirical distribution of informative messages ("I will choose $r$ " and "I will choose $l$ ") in both treatments. In both cases communication is widely used by senders, since no subject has abstained from sending at least one informative message. The number of messages sent by each subject is relatively high, ranging from 5 messages to 10 messages in the baseline treatment and from 8 to 10 messages in the oath treatment. In particular, 14 subjects out of $30(46.7 \%)$ in the baseline treatment send 10 informative messages, i.e. one such message in every round; 22 subjects out of $30(73 \%)$ do so in the oath treatment. The difference is significant according to a bootstrap test for equality of proportions $(p=.067)$. Overall, although senders in the oath treatment seem to use communication more often than senders in the baseline treatment, first-order dominance of the EDF of informative messages in the oath treament over informative 
Figure 3: Decisions of ReCEIVERs And SEnders by treatment

(a) Receivers

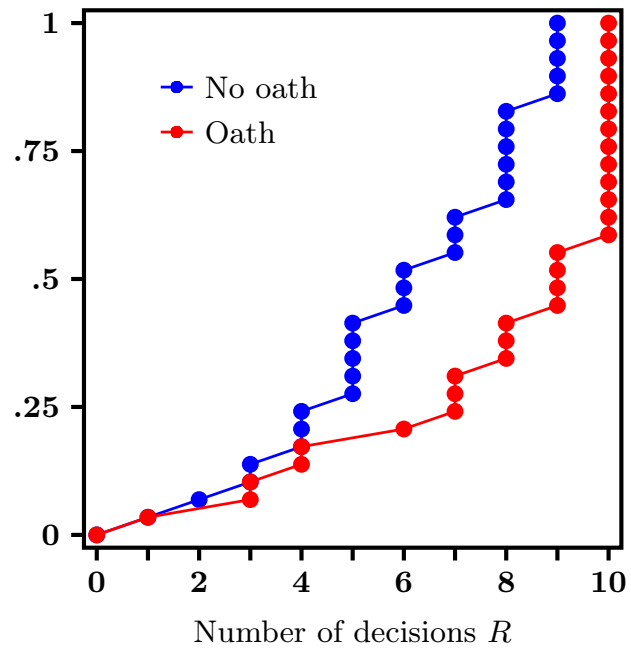

(b) Senders

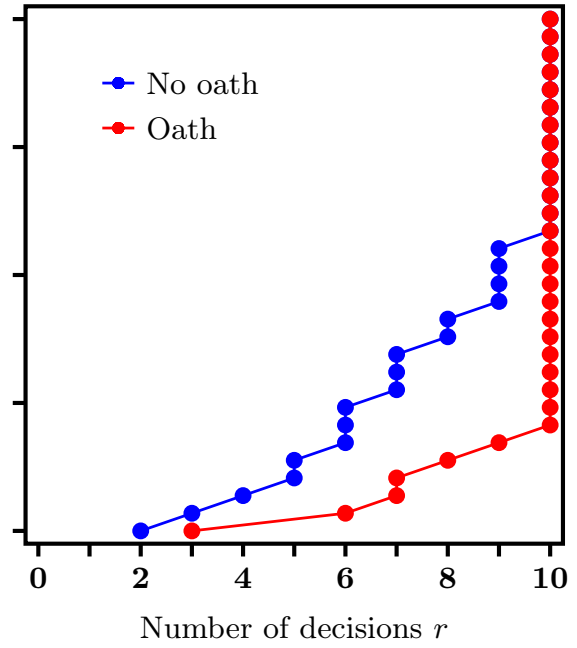

messages in baseline is not statistically significant $(p=.118) 12$ Figure $2 \mathrm{~b}$, in turn, presents the analogous EDF exclusively for messages "I will choose $r$ ". We find that subjects in the oath treatment display a stronger willingness to signal their credibility than subjects in the baseline treatment: for this class of messages, the EDF from the oath treatment first-order dominates the EDF from the baseline treatment $(p=.035)$. Finally, Figure 2.c focuses on messages "I will choose $l$ ". These messages are seldom used - only 3 subjects out of 30 send them at least once in the oath treatment, whereas 12 of them out of 30 do so in the baseline; this difference is significant at the $5 \%$ level $(p=.012)$. Altogether, we find that the individual communication behavior does not vary much in quantity - since senders use communication to a similar extent in both treatments but does change in quality - in the oath treatment messages "I will choose $r$ " are sent significantly more often, while messages "I will choose $l$ " are sent significantly less often.

Result 2 The oath both (1) increases the informativeness of transmitted signals, and (2) changes the signal's structure by substantially increasing the use of reassuring announcements.

Figures 3.a and 3.b summarize both players' decision-making patterns. The degree of player receivers' reliance is larger in the oath treatment: out of 10 decisions, an average of 5.9 decisions $R$ is observed in the baseline treatment, and 7.7 in the oath treatment. A mean difference bootstrap test indicates that the difference is significant $(p=.029)$. Both EDF presented in Figures 3 a

\footnotetext{
${ }^{12}$ This result comes from a bootstrap version of the univariate Kolmogorov-Smirnov test. This modified test provides correct coverage even when the distributions being compared are not entirely continuous and, unlike the traditional Kolmogorov-Smirnov test, allows for ties (see Abadie, 2002, Sekhon, 2011).
} 
Figure 4: Truthfulness of senders by treatment (Empirical Distribution function)

(a) All informative messages

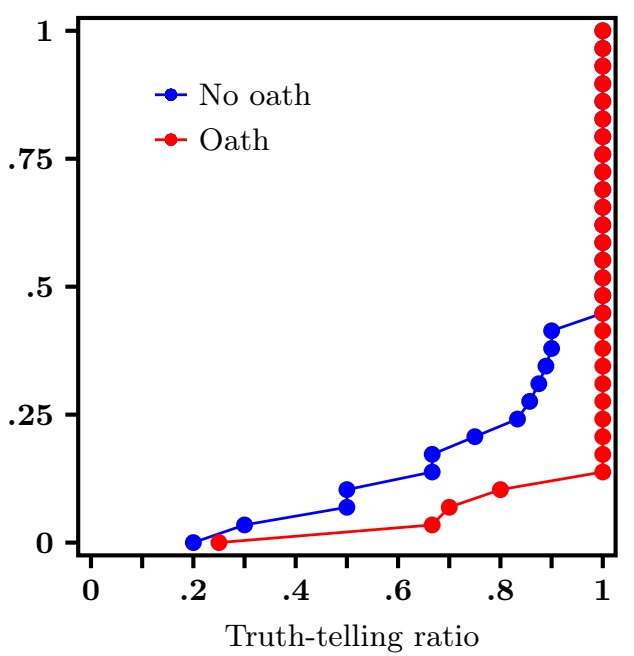

(b) Only "I will choose $r$ "

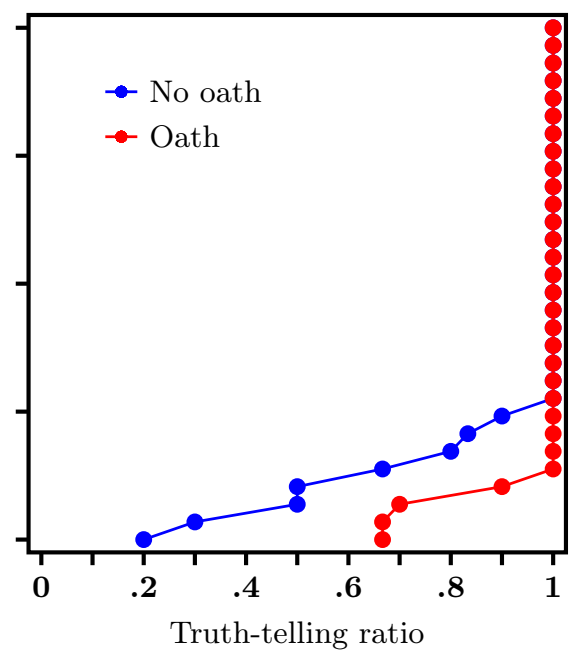

are similar on the low end, i.e for players who do not play $R$ often, while discrepancies are visible on the upper end, where the oath treatment induces subjects to play $R$ more often. We observe that $43.3 \%$ of receivers in the oath treatment choose to play $R$ in all rounds while none of them do so in the baseline treatment (bootstrap proportion test: $p=.000$ ). The differences between the two EDF are highly significant: the EDF of receivers' behavior in the oath treatment firstorder dominates the EDF of receivers' behavior in the baseline $(p=.003)$. Substantial differences also appear in senders' behavior, as revealed in Figure 3 b. Based on the empirical frequencies of decisions $r$, we find that the EDF from the oath treatment first-order dominates the EDF from baseline $(p=.017)$. Therefore, in the presence of oath senders are more likely to cooperate with receivers. In particular, $80 \%$ of senders choose to play $r$ in all 10 rounds in the oath treatment, while only $43.3 \%$ do so in the baseline. A bootstrap test for equality of proportions indicates that the difference is significant at the $1 \%$ level (bootstrap proportion test: $p=.006$ ).

Result 3 The oath shifts sender's actions towards more payoff maximizing decisions.

We now explore the link between messages and actions through the truth-telling behavior of senders. For sender we calculate the proportion of cases in which the action is coherent with the message (given it is informative) within all the cases in which an informative message is sent. We call this the truth-telling ratio; Figure 4 . a presents the EDF from both treatments. Looking at the figure, we find striking evidence that misinforming one's partner about intended move is substantially more widespread without the oath. First, 26 of 30 senders (87\%) always reveal their actual intentions when sending an informative message in the oath treatment relative to only 17 
Figure 5: Messages trusted by player As (Empirical distribution function)

(a) All informative messages

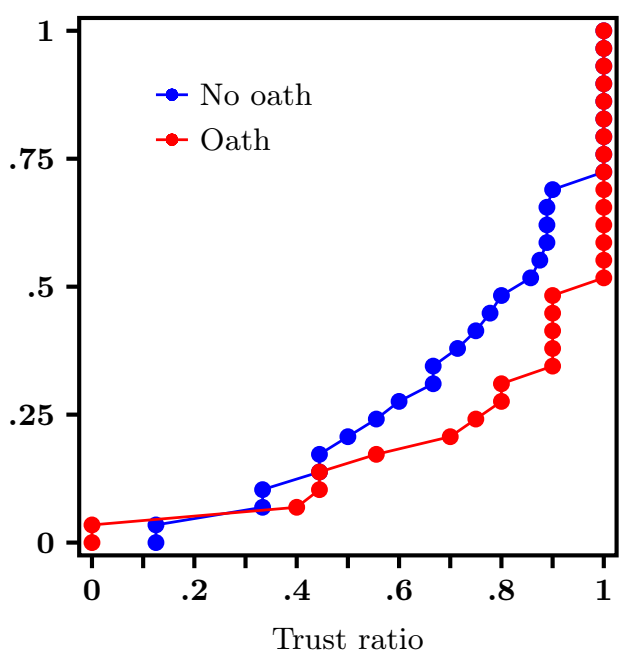

(b) Only "I will choose $r$ "

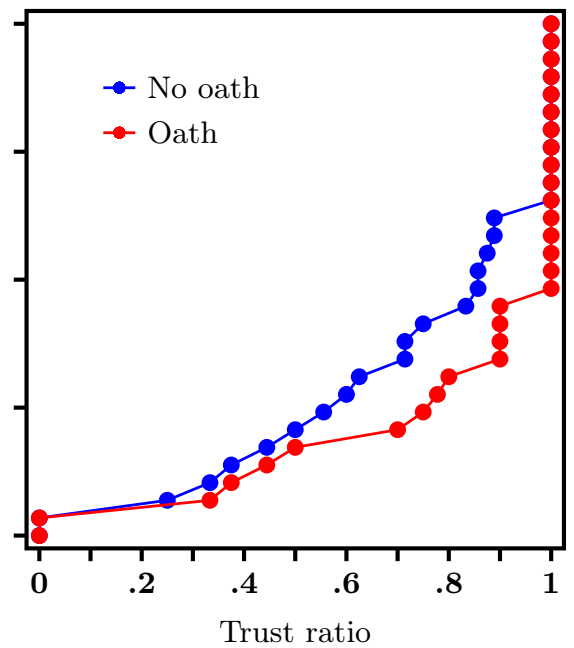

of 30 player Bs $(57 \%)$ in the baseline treatment. The difference is statistically significant with $p=0.016$ according to a bootstrap proportion test. Second, the EDF from the oath treatment significantly first-order dominates the EDF from baseline $(p=0.067)$. In Figure 4 . b, we represent the same truth-telling ratio using only messages "I will choose $r$ ". Here the difference between the two treatments is more ambiguous. The EDF of the truth-telling ratio from the oath treatement still first-order dominates the EDF from baseline, but the result is not statistically significant $(p=0.586)$.

Result 4 The oath improves the truthfulness of announcements.

Last, in Figures 5 a and 5.b, we look at receivers' perception of information obtained from their partners, conditional on the presence of oath. More precisely, for each individual in the role of the receiver we calculate the proportion of cases in which she gives the best response to an informative signal (that is, when the receiver plays $R$ should the signal from the sender announce action $r$, or receiver's move $L$ follows message announcing move $l$ by sender) among all the cases when the received message happens to be informative. We call this proportion the trust ratio, and present its EDF in Figures 5 a and 5.b. The first figure suggests that oath has an influence on how receivers react to messages: the EDF obtained in the oath treatment first-order dominates the EDF obtained in the baseline $(p=.035)$. This remains true when restricting attention to messages "I will choose $r$ ", as it can be seen in the second figure. The differences in behaviors are less pronounced but still significant $(p=.067)$.

Result $\mathbf{5}$ The oath improves the receiver's trust toward the announcement. 


\section{Conclusion}

Overcoming coordination failure through economic design can be enhanced with more insight into non-monetary commitment devices. If people can freely choose their coordination partner, they can choose people they already know are trustworthy, so commitment is guaranteed and coordination is efficient (see Riedl, Rohde, and Strobel, 2011). But in many cases, people must coordinate with people they do not know. Now the commitment to backing words with deeds is unclear, which leads to more coordination failure. This paper investigates whether the social psychological idea of commitment via a truth-telling oath can improve how communication reduces strategic uncertainty, thereby increasing coordination on efficient outcomes. We create commitment by having our players sign a voluntary oath to tell the truth prior to entering the laboratory (Jacquemet, Joule, Luchini, and Shogren, 2009). Our results suggest that the truth-telling oath significantly increased optimal coordination by nearly 50 percent.

But the oath had an asymmetric effect on behavior. A sender was more likely to send informative and reassuring messages, and then back up his words with actions. In contrast, a receiver was less likely to change his behavior. A few more receivers trusted the messages received under oath than without, but still half of them remained wary. The oath appears to create stronger commitment in senders' signals/actions than in receivers' responses. Commitment theory reveals the limits of communication as a coordination device. Commitment increased the efficiency of communication by making the supply more trustworthy and reliable. But improved supply-side

communication did not translate into $100 \%$ efficiency in the coordination game itself. This suggests limits still exist to communication from the demand side.

\section{References}

ABAdie, A. (2002): "Bootstrap Tests for Distributional Treatment Effects in Instrumental Variable Model," Journal of the American Statistical Association, 97(457), 284-292.

Aumann, R. (1990): "Nash Equilibria Are Not Self-Enforcing," in Economic Decision-Making: Games, Econometrics, and Optimization: Contributions in Honor of Jacques H. Dreze, ed. by J. J. Gabszewic, J.-F. Richard, and L. A. Wolsey, pp. 201-206. North-Holland, Amsterdam.

Beard, T. R., and J. Beil, Richard O. (1994): "Do People Rely on the Self-Interested Maximization of Others? An Experimental Test," Management Science, 40(2), 252-262.

Beard, T. R., R. O. J. Beil, and Y. Mataga (2001): "Reliant behavior in the United States and Japan," Economic Inquiry, 39(2), 270-279.

Burger, J. M. (1999): "The Foot-in-the-Door Compliance Procedure: A Multiple-Process Analysis and Review," Personality and Social Psychology Review, 3(4), 303-325. 
Charness, G., And M. Dufwenberg (2006): "Promises and Partnership," Econometrica, 74(6), 15791601.

Cialdini, C., J. Bassett, R. Miller, And J. Miller (1978): "Low-ball procedure for producing compliance: Commitment, then cost," Journal of Personality and Social Psychology, 36(5), 463-476.

Cialdini, R., And B. Sagarin (2005): "Interpersonal influence," in Persuasion: Psychological insights and perspectives, ed. by T. Brock, and M. Green, pp. 143-169. Sage Press, Newbury Park, CA.

Cooper, R., D. V. DeJong, R. Forsythe, and T. W. Ross (1992): "Communication in Coordination Games," Quarterly Journal of Economics, 107(2), 739-771.

Cooper, R. W., D. V. DeJong, R. Forsythe, And T. W. Ross (1990): "Selection Criteria in Coordination Games: Some Experimental Results," American Economic Review, 80(1), 218-233.

Crawford, V. (1998): "A Survey of Experiments on Communication via Cheap Talk," Journal of Economic Theory, 78(2), 286-298.

Devetag, G., And A. Ortmann (2007): "When and why? A critical survey on coordination failure in the laboratory," Experimental Economics, 10(3), 331-344.

Duffy, J., And N. Feltovich (2002): "Do Actions Speak Louder Than Words? An Experimental Comparison of Observation and Cheap Talk," Games and Economic Behavior, 39(1), 1-27.

Ellingsen, T., And M. Johannesson (2004): "Promises, Threats and Fairness," Economic Journal, 114(495), 397-420.

Ellingsen, T., And R. Östling (2010): "When Does Communication Improve Coordination?," American Economic Review, 100(4), 1695-1724.

Farrell, J., ANd M. Rabin (1996): "Cheap Talk," Journal of Economic Perspectives, 10(3), 103-118.

Goeree, J. K., And C. A. Holt (2001): "Ten Little Treasures of Game Theory and Ten Intuitive Contradictions," American Economic Review, 91(5), 1402-1422.

Greiner, B. (2004): "An Online Recruitment System for Economic Experiments.," in Forschung und wissenschaftliches Rechnen 2003. GWDG Bericht 63, ed. by K. Kremer, and V. Macho, pp. 79-93. Ges. für Wiss. Datenverarbeitung, Göttingen.

Jacquemet, N., A. James, S. Luchini, And J. Shogren (2010): "Referenda under oath," GREQAM $W P, 10(15)$.

Jacquemet, N., R.-V. Joule, S. Luchini, And J. Shogren (2009): "Eliciting Preferences under Oath," CES Working paper, 09(43).

JACQUemet, N., AND A. Zylbersztejn (2010): "Learning, words and actions: experimental evidence on coordination-improving information," CES Working Paper, 2010(64). 
(2011): "What drives failure to maximize payoffs in the lab? A test of the inequality aversion hypothesis?," CES Working Paper, 2011(36).

Joule, R., AND J. Beauvois (1998): La soumission librement consentie. Presses Universitaires de France, Paris.

KAmecke, U. (1997): "Rotations: Matching schemes that efficiently preserve the best reply structure of a one shot game," International Journal of Game Theory, 26(3), 409-417.

Parkhurst, G. M., J. F. Shogren, and C. Bastian (2004): "Repetition, Communication, and Coordination Failure," Experimental Economics, 7(2), 141-152.

Riedl, A., I. M. T. Rohde, And M. Strobel (2011): "Efficient Coordination in Weakest-Link Games," CESifo Working Paper, (3685).

Rosenthal, R. W. (1981): "Games of perfect information, predatory pricing and the chain-store paradox," Journal of Economic Theory, 25(1), 92-100.

Schelling, T. (1960): The strategy of conflict. Harvard University Press, Cambridge, MA.

Sekhon, J. (2011): "Multivariate and Propensity Score Matching Software with Automated Balance Optimization," Journal of Statistical Software, 42(7), 1-52.

SElten, R. (1975): "Reexamination of the perfectness concept for equilibrium points in extensive games," International Journal of Game Theory, 4(1), 25-55.

Vanberg, C. (2008): "Why Do People Keep Their Promises? An Experimental Test of Two Explanations," Econometrica, 76(6), 1467-1480.

Zeiliger, R. (2000): "A presentation of Regate, Internet based Software for Experimental Economics," http://www.gate.cnrs.fr/zeiliger/regate/RegateIntro.ppt, GATE. 